\title{
RESPONSABILIDADES \\ ADMINISTRATIVAS, SU IMPORTANCIA \\ EN EL CONTEXTO DEL SISTEMA \\ NACIONAL DE FISCALIZACIÓN
}

\section{ADMINISTRATIVE RESPONSIBILITY, THEIR IMPORTANCE OF THE NATIONAL INSPECTION.}

Mtra. Guadalupe Inés Solís Salazar ${ }^{\text {a }}$

Mtra. Rosa María Solís Salazar ${ }^{\text {b }}$

Mtra. Amanda Nieves Alcalá Osorio ${ }^{c}$

Mtro. Víctor Hugo Aguilar Hernández ${ }^{\text {d }}$

\author{
${ }^{a}$ Benemérita Universidad Autónoma de Puebla \\ Facultad de Contaduría Pública, contaduria.solis@gmail.com \\ ${ }^{\mathrm{b}}$ Benemérita Universidad Autónoma de Puebla \\ Facultad de Contaduría Pública, rosi.solis@me.com \\ ${ }^{\mathrm{c}}$ Benemérita Universidad Autónoma de Puebla \\ Facultad de Contaduría Pública, amandanao@hotmail.com \\ d Benemérita Universidad Autónoma de Puebla \\ Facultad de Contaduría Pública, victorhaguilarh@hotmail.com
}

Fecha de aceptación: 9 de junio de 2020

\section{RESUMEN}

El crecimiento de la corrupción en México ha dado origen a acciones gubernamentales para combatirla, lo anterior vincula a la Ley General de Responsabilidades Administrativas (LGRA) desde un enfoque de Rendición de Cuentas con el Sistema Nacional de Fiscalización (SNF) unido al Sistema Nacional Anticorrupción(SNA), este último da origen a modificaciones de ordenamientos existentes y leyes, de ahí el interés de analizar la Ley General de Responsabilidades Administrativas (LGRA), cuyo objeto es señalar las responsabilidades administrativas de los servidores públicos y de los particulares, tipificando cada falta y sanción que se aplicará un vez investigada y calificada. Este estudio es una recopilación documental para analizar el contenido de la ley, su impacto en 
la prevención de la corrupción, así como dar a conocer la importancia de las responsabilidades administrativas en que pueden verse involucrados servidores públicos y particulares, también se muestran datos de las actuaciones de los servidores públicos, sin embargo, es de suma importancia una vez analizada la información documental, proponer alguna acción coadyuvante a las acciones establecidas en la LGRA e involucrar a jóvenes estudiantes en la participación ciudadana, apoyando acciones de combate a la corrupción.

PALABRAS CLAVE: Responsabilidad administrativa; Servidores Públicos; Particulares; Corrupción; Sanciones.

\section{ABSTRACT}

The growth of corruption in Mexico has given rise to government actions to combat it, the foregoing links to the General Law of Administrative Responsibilities (LGRA) from an Accountability approach with the National Control System (SNF) together with the National Anticorruption System (SNA), the latter gives rise to modifications of existing regulations and laws, hence the interest in analyzing the General Law of Administrative Responsibilities (LGRA), whose purpose is to indicate the administrative responsibilities of public servants and individuals, typifying each fault and sanction that will be applied once investigated and qualified. This study is a documentary compilation to analyze the content of the law, its impact on the prevention of corruption, as well as to publicize the importance of administrative responsibilities in which public servants and individuals may be involved, data on the However, once the documentary information has been analyzed, it is of the utmost importance to propose some action that contributes to the actions established in the LGRA and to involve young students in citizen participation, supporting actions to combat corruption.

KEYWORDS: Administrative responsibility, Public Servants; Individuals; Corruption; Sanction.

\section{INTRODUCCIÓN}

En México existe una preocupación general respecto del actuar de la Administraciónn 
Pública, tanto como en su papel de administrador y ente rector de las relaciones con el Estado y en su esfera de Derecho Privado, en el momento en que suscribe relaciones con los particulares para un beneficio colectivo. En ese sentido se vuelve esencial el estudio y el análisis de la responsabilidad administrativa por la naturaleza de la Administración Pública.

Podemos definir a la responsabilidad como el acto de responder por una serie de obligaciones a las cuales un ente jurídico se encuentra sujeto, así, la responsabilidad administrativa necesariamente implica el acto por el cual la Administración Pública en sus tres niveles de gobierno responde por los actos jurídicos que emanan de su accionar cotidiano en su calidad de derecho público como de derecho Privado.

El estudio de la responsabilidad administrativa se encuentra debidamente justificado si atendemos la preocupación por el crecimiento de la corrupciónn en México, así como el nacimiento del Sistema Nacional Anticorrupción (SNA) y permite que existan los mecanismos para sancionar la comisión del delito o faltas administrativas desde una perspectiva de abuso de facultades conferidas a la administración, tales como el objetivo de obtener un beneficio de carácter preferencial frente a otros sujetos, lo que deriva en una inobservancia de procedimientos establecidos en leyes, reglamentos, decretos y demás compendios normativos, actualmente tanto por parte de los servidores públicos como entes de derecho privado.

Por ello surge, la necesidad de comprender el vínculo que une la Ley General de Responsabilidades Administrativas (LGRA) (Unión, LEY GENERAL DE RESPONSABILIDADES ADMINISTRATIVAS , 2016), desde el enfoque de la Rendición de Cuentas y a partir del Sistema Nacional de Fiscalización (SNF), entendiéndolo con el fin de transparentar el actuar de los entes públicos y examinar a las instituciones con el fin de que no existan conductas que encuadren dentro de una Responsabilidad Administrativa, así como regular y sancionar el accionar de los servidores públicos, y en consecuencia, para cumplir con sus fines para los cuales fueron creados.

Ante los casos y hechos de corrupción que se dan a conocer cada día en los medios de 
comunicación, pareciera que los ciudadanos no están vinculados a estos hechos y solo es atribuible a los servidores públicos ,sin embargo, en la colusión de un acto de corrupción se necesitan dos partes, quien está en la posición de poder dar paso a la acción a través de un permiso, autorización, dejar de hacer o bien una adjudicación, teniendo de la otra parte el ofrecimiento, promesa o entrega de un beneficio o ventaja. El interés es divulgar que todos particulares y ciudadanos, se puede estar en el supuesto de faltas administrativas graves señaladas en la LGRA, contenidas de forma clara para servidores públicos y para particulares vinculados a estas faltas, la medida es que todos conozcan las sanciones que se imponen pudiendo ser un paso para prevenir hechos de corrupción y frenar este problema que se ha incrementado, perjudicado a nuestro país, en donde solo se han beneficiado élites de poder. Es de suma trascendencia difundir las tareas que se han emprendido a partir del año 2015 a través de la puesta en marcha del Sistema Nacional de Fiscalización (SNF) y el Sistema Nacional Anticorrupción (SNA), con acciones coordinadas entre los entes fiscalizadores tanto del poder ejecutivo como el legislativo, con la participación de la Secretaría de la Función Pública (SFP) y la Auditoria Superior de la Federación (ASF), contando con la participación de la ciudadanía del Comité de Participación ciudadana que se señala en el SNA, con una ley normativa que impone sanciones, que se mencionan en la LGRA (Unión, LEY GENERAL DE RESPONSABILIDADES ADMINISTRATIVAS , 2016), y como consecuencia de estas acciones se reflejarán los resultados del combate a la corrupción, entendiéndose que todos los ciudadanos estamos inmersos en el problema y por ende la participación de todos es ineludible e inexcusable. Por otra parte la participación ciudadana es un elemento fundamental que contribuye a cambios trascendentales, sin embargo, no todos los ciudadanos se interesan en ella por lo tanto, en importante direccionar acciones de vigilancia de las acciones gubernamentales para prevenir actos de corrupción, destacando que los estudiantes si ejercen la participación ciudadana, son capaces de organizarse, sin ningún otro interés que el solo ser escuchados y de ahí se deriven las acciones de cambio que se persiguen.

Este trabajo de divulgación tiene la finalidad de sensibilizar a los servidores públicos y particulares, respecto de las responsabilidades administrativas señaladas en la LGRA.

Así como. dar a conocer el objeto de la LGRA, así como mencionar las faltas 
administrativas graves y no graves en que pueden verse involucrados los servidores públicos y los particulares, con la finalidad de señalar las sanciones a las faltas administrativas y sensibilizar para promover acciones que inhiban la corrupción.

\section{CONCEPTUALIZACIÓN DE LA RESPONSABILIDAD ADMINISTRATIVA}

\section{1 Responsabilidad Administrativa}

Para comprender la importancia de la Responsabilidad Administrativa, debemos entender la naturaleza de la Administración Pública, la cual desde su nacimiento como instituciones de Estado regulan y gestionan sus acciones en un ámbito de derecho público como de derecho privado, generando las condiciones para el correcto funcionamiento del Estado y sus elementos que lo integran.

De ahí que la importancia de la Administración Pública estriba en que dichas instituciones cuentan con un vínculo de mandato conferido por la población con el objeto de realizar las actividades y necesidades de la colectividad, mismo que se debe enfocar a los lineamientos y ordenamientos que definan sus actividades. Así el ejercicio de la Administración Pública se puede abordar desde su actuar como ente de Derecho público y como ente de Derecho Privado, como se señala a continuación:

1. Es de Derecho Público cuando es un administrador y un ejecutor de las relaciones entre la sociedad con los órganos públicos y sus facultades conferidas por las leyes y codificaciones, como ejemplo se puede mencionar su papel de policía o autoridad hacendaria, observando que los entes Administrativos en su papel de derecho público tienen la función de vigilar, regular, administrar y en su caso sancionar conforme a las leyes aplicables.

2. En su actuar se traslada al Derecho Privado, su accionar de los entes administrativos se convierte en un comportamiento al nivel de los particulares, generalmente con el 
fin de celebrar relaciones contractuales, licitaciones o incluso fideicomisos en los cuales los entes Administrativos son parte y no un regulador, persiguiendo un beneficio mutuo.

3. El Derecho Administrativo nos permite regular el comportamiento de los entes de la Administración Pública en sus dos esferas jurídicas y en su defecto las consecuencias que de ellos emanen, siendo en esta investigación la observancia u omisión a los ordenamientos legales aplicables y que pudieran generarse responsabilidades y en su defecto la comisión de conductas delictivas, por lo que resulta necesario el análisis y el estudio de la Responsabilidad Administrativa.

Existen muchas definiciones del término responsabilidad, sin embargo, es necesario atender el contexto de la acepción respecto de la Administración Pública, en ese sentido, define Herbert H. L. Hart a la responsabilidad como:

"la existencia de leyes que definen ciertas formas de conducta como algo que debe ser omitido o realizado por aquellos a quienes se aplica, incurriendo en una infracción al derecho si se presenta una desobediencia al respecto, por lo cual se tiene que responder ante las consecuencias de una infracción en comento, que conlleva precisamente la imposición de una pena o sanción que busca crear un motivo para que los hombres adecuen su conducta a las prescripciones normativas (Hart, 1998, pág. 34)

En ese sentido, podemos entender de manera análoga a la Responsabilidad como un acto de responder por ciertas obligaciones que le son conferidas a la Administración Pública en su accionar como ente de Derecho Público, como de Derecho Privado, lo anterior desde una óptica de lo que responsabilidad conlleva necesariamente a una sanción por la acción u omisión que deriva necesariamente en una infracción al ente que comete la misma.

Así las cosas, podemos inferir que existe responsabilidad administrativa cuando cualquier ente de la Administración Pública, en el carácter de Derecho Público o Privado, mediante la acción u omisión de algún ordenamiento jurídico o mediante la comisión de alguna conducta genera un beneficio para sí o para terceros que al mismo tiempo genere un 
perjuicio a otros y que pueda derivar en un ilícito, lo que deriva en una ventaja o desventaja

\section{2 SNF y SNS, coadyuvantes para combatir la corrupción.}

El enfoque de la Responsabilidad Administrativa con el paso del tiempo ha generado el nacimiento de instituciones y ordenamientos legales que analizan las sanciones por el incumplimiento o la obtención de beneficios a través de actos ilícitos en los que pueden incurrir los entes de la administración pública tales como el Sistema Nacional Anticorrupción (SNA), el Sistema Nacional de Fiscalización (SNF), o la Ley General de Responsabilidades Administrativas (LGRA).

El SNA surge como un ente de coordinación entre organismos de la Administración Pública de todos los niveles de gobierno con el fin de prevenir, detectar y sancionar faltas administrativas y hechos de corrupción, así como en la fiscalización y control de recursos públicos, diseñando políticas públicas que prevengan actos de corrupción, vigilando su implementación y midiendo el éxito de estas.

El Sistema Nacional Anticorrupción nace en el año 2016 con el fin de atener y prevenir la corrupción. En efecto, como se aprecia en la Exposición de motivos de la Ley General del Sistema Nacional Anticorrupción(LGSNA) (Unión, Ley General del Sistema Nacional Anticorrupción , 2016), la intención de su nacimiento es crear políticas de prevención de la corrupción y que los servidores públicos realicen sus atribuciones desde un marco de legalidad donde en lo posible disminuya y se erradique la arbitrariedad de estos y sus atribuciones y que estás a su vez se realicen mediante un esquema de justicia, entendiendo al fenómeno de corrupción como un fenómeno entre entes y particulares que atenta a la debilidad de las instituciones, la que se puede dar por distintos factores y que genera conductas ilícitas que en gran medida resultan impunes.

El Sistema Nacional de Fiscalización se creó con el fin de formar un frente común entre los órganos de gobierno y desde todos los ámbitos de su competencia, con el fin de examinar, 
articular, transparentar y vigilar la gestión gubernamental, así como el uso de los recursos públicos, mejorando la rendición de cuentas a nivel nacional, surge en el año 2015.

El artículo 3 fracción XXII, de la LGSNA define al Sistema Nacional de Fiscalización (SNF), como:

“el conjunto de mecanismos interinstitucionales de coordinación entre los órganos responsables de las tareas de auditoría gubernamental en los distintos órdenes de gobierno, con el objetivo de maximizar la cobertura y el impacto de la fiscalización en todo el país, con base en una visión estratégica, la aplicación de estándares profesionales similares, la creación de capacidades y el intercambio efectivo de información, sin incurrir en duplicidades u omisiones” (Unión, Ley General del Sistema Nacional Anticorrupción , 2016).

Dentro de las metas que engloban al SNF, destaca la creación de capacidades, mejoras a normatividad, profesionalización de éstas con el fin de fiscalizar a los entes administrativos y gubernamentales en la prevención y el combate a la corrupción, mediante la transparencia oportunidad, imparcialidad, confiabilidad de su accionar.

Como podemos observar, tanto el Sistema Nacional Anticorrupción como el Sistema Nacional de Fiscalización nacen con el objeto de prevenir conductas ilícitas, y prevenir la existencia de responsabilidades administrativas mediante la vigilancia del accionar de los servidores públicos bajo los principios rectores del servicio público. Así, el artículo 5 señala como principios rectores del servicio público los siguientes:

"legalidad, objetividad, profesionalismo, honradez, lealtad, imparcialidad, eficiencia, eficacia, equidad, transparencia, economía, integridad y competencia por mérito. Los Entes públicos están obligados a crear y mantener condiciones estructurales y normativas que permitan el adecuado funcionamiento del Estado en su conjunto, y la actuación ética y responsable de cada servidor público” (Unión, Ley General del Sistema Nacional Anticorrupción , 2016).

La ley General de Responsabilidades Administrativas surge con el fin de combatir conductas ilícitas en la función pública, tipificándolas y estableciendo acciones que 
prevengan estas. Así, establece directrices que permitan que los servidores públicos realicen sus actividades mediante un marco de legalidad y transparencia (Unión, LEY GENERAL DE RESPONSABILIDADES ADMINISTRATIVAS , 2016).

Si atendemos a la exposición de motivos de la Ley General de Responsabilidades Administrativas, se debe entender que cuando existe un acto ilícito necesariamente implica un accionar tanto de un ente particular como de derecho público que derive en un beneficio o aprovechamiento o abuso de facultades conferidas, de tal suerte que el objetivo de la ley es establecer los lineamientos para el actuar de los servidores públicos. No obstante, el enfoque de la Ley General de Responsabilidad Administrativa se ha vuelto integral incluyendo las acciones también de los particulares sean personas físicas o morales que incurran en ilícitos o conductas que pudieran derivar en una responsabilidad administrativa.

Este enfoque se debe entender desde la perspectiva de que el ente público interactúa con el particular tanto como órgano rector, estableciendo relaciones contractuales, lo que implica necesariamente en esa omisión de ordenamientos jurídicos que generen un beneficio para el particular, dicha perspectiva resulta necesaria si se pretende el cumplimiento del fin último de las instituciones supra referidas, toda vez que como se puede inferir, a toda acción corresponde una reacción y para que exista una responsabilidad necesariamente debe existir un beneficio o un perjuicio a un particular.

El análisis anterior necesariamente implica la interacción de dos figuras, tanto el órgano de derecho público como el particular, que mediante una conducta incita a la omisión de la norma, empero la responsabilidad administrativa no necesariamente se puede presentar de esa forma, sino también mediante el abuso de facultades conferidas, un ejemplo de ello lo puede ser en el abuso de facultades de policía, o en el abuso de la fiscalización, pero lo que se puede advertir es que dicha responsabilidad implicara que el ente público se encuentre en una esfera de vigilante y rector.

En efecto, desde esa perspectiva, encuentra su sustento la fiscalización, toda vez que, al fiscalizar, entendida esta figura como una vigilancia a las actividades gubernamentales, se verifica que las acciones de los organismos de gobierno actúen conforme a su norma y 
respeten los lineamientos establecidos, evitando un abuso de autoridad y en consecuencia incurrir en responsabilidades y delitos, los que en el caso sean aplicables.

Un ejemplo de fiscalización resultan las auditorias gubernamentales, necesarias para la vigilancia de que los recursos económicos con los que cuentan los órganos de la administración pública sean aplicados conforme a la norma, así como respetando los lineamientos del Consejo Nacional de Armonización Contable (México, 2021), y en caso de que exista una incorrecta aplicación de los mismos se pueda establecer procedimientos sancionadores que establece la LGRA.

En ese tenor, se puede apreciar el vínculo que une a la ley con el SNF, en el entendido que este órgano establece directrices que prevengan las conductas ilícitas que se pueden generar con el actuar cotidiano de la función pública, dándoles certeza jurídica mediante el reconocimiento de estas facultades a través de la LGSNA, así como la LGRA.

No obstante, es necesario hacer énfasis en el hecho que la Ley en mención, anteriormente se enfocaba en Responsabilidad de Servidores Públicos, atendiendo únicamente a la relación de mandato inherente al actuar de la función pública, y exclusivamente al ente de la administración pública, dejando la conducta de los particulares al derecho privado, empero el cambiar el enfoque a responsabilidades administrativas vuelve más eficientes las medidas preventivas con las que fue creado el SNF así cómo prevenir de manera más integral las conductas sujetas a responsabilidades administrativas, al sancionar no solo al ente público sino también al particular, tal y como se aprecia de las sanciones contenidas en la LGRA tanto para servidores públicos como particulares.

\section{3 Faltas Administrativas.}

Se señala en la Ley General de Responsabilidades Administrativas (LGRA), en el Sistema Nacional de Fiscalización (SNF) y el Sistema Nacional Anticorrupción (SNA), que los entes públicos deben contar y en su caso fortalecer condiciones estructurales y normativas, permitiendo el cabal funcionamiento del Estado en su conjunto, haciendo énfasis de la 
actuación ética y responsable, desde el puesto, cargo o comisión de cada servidor público, en este punto de las directrices, se debe trabajar de manera ardua, es importante retomar todos los valores de cada persona para llevarlos a su campo de trabajo, sobre todo el individuo en su actuar laboral donde se ve inmerso en el manejo de recursos públicos, debe promover y adoptar un grupo de principios, como se muestra a continuación en la figura 1 .

\section{Figura 1}

Grupo de principios
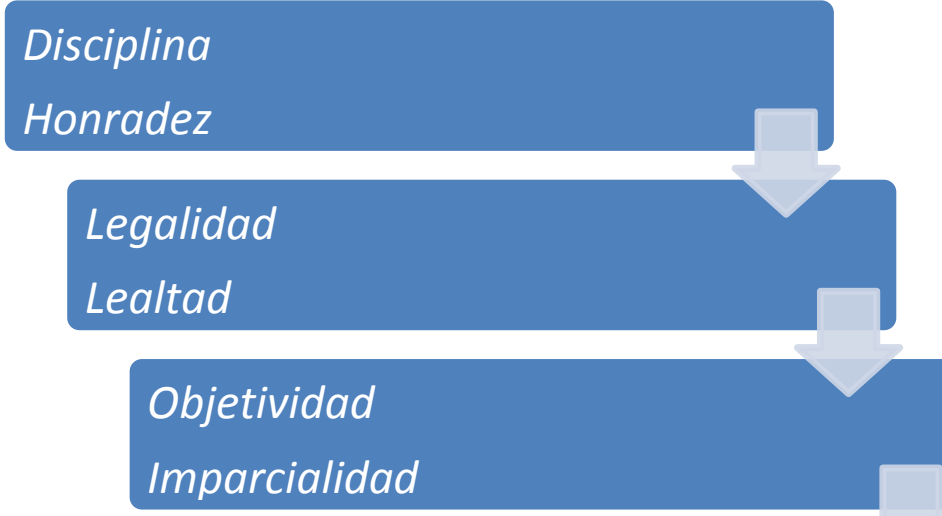

\section{Profesionalismo}

\section{Integridad}

\section{Rendición de cuentas}

\section{Eficiencia y Eficacia}

Fuente: Elaboración Propia con información del artículo 7 de la LGRA. (Unión, Ley General del Sistema Nacional Anticorrupción, 2016)

La LGSNA (Unión, Ley General del Sistema Nacional Anticorrupción , 2016), en su Art. 2, fracción II), señala que es objeto de la misma "establecer las base mínimas para la prevención de hechos de corrupción y faltas administrativas, por lo tanto es en la LGRA (Unión, LEY GENERAL DE RESPONSABILIDADES ADMINISTRATIVAS , 2016) , donde en primera instancia se señalan las directrices que deben observar los Servidores Públicos para cumplir con la observancia de los principios señalados en la figura 1, implicando el deber de : actuar conforme a las leyes y demás ordenamientos; conducirse con rectitud, no buscar obtener beneficios adicionales a lo que su puesto, cargo o comisión le otorga; estar siempre atendiendo las necesidades colectivas y no el interés personal; dar 
un trato digno a todos actuando con una cultura de servicio; entre otros. Es competencia de la LGRA tipificar es el tipo de faltas administrativas que serán sujetas a investigación, substanciación (calificación) y sanción, en caso de encontrarse en el supuesto normativo los servidores públicos o por particulares, siendo estas personas físicas o personas morales.

Otro punto de enlace entre el SNA y la LGRA, se localiza cuando señala que cada Secretaría u órganos internos de control deben establecer mecanismos de prevención para orientar el comportamiento de los servidores públicos en situaciones concretas de su actuación, por otra parte se hace especial énfasis que todos los entes públicos deben contar con un Código de Ética, elaborado conforme a los lineamientos que emita el SNA, darlo a conocer y debe ser de observancia obligatoria para los servidores públicos, considerando que serán las Secretarías y los órganos internos de control los responsables de evaluar cada año las acciones que conduzcan a un cabal cumplimiento, como atender las recomendaciones que haga el Comité Coordinador del SNA, a fin de fortalecer las acciones en prevención de Faltas Administrativas, avances y resultados.

También contempla la LGRA, los mecanismos de rendición de cuentas de los Servidores Públicos, contemplando el sistema de evolución patrimonial, de declaración de intereses y constancias de presentación de declaración fiscal, lo cual se lleva a cabo a través de una plataforma en donde los Servidores Públicos deben de manera inicial, periódica y final de acuerdo a su estancia en el puesto, cargo o comisión, presentar en las fechas establecidas y con la información solicitada, resumiéndose en las siguientes declaraciones: evolución patrimonial, declaración de intereses y constancia de la presentación de la declaración fiscal.

Existen dos categorías de faltas administrativas: Faltas Administrativas No Graves y Faltas Administrativas Graves, siendo que las faltas administrativas no graves, están contenidas en los artículos 49 y 50 de la LGRA, refiriéndose a las que van en contra del cumplimiento de las obligaciones de los servidores públicos, como también se considera los daños y perjuicios por negligencia o culpa incurra un servidor público sin llegar a estar considerada en la lista de faltas administrativas. Es conveniente resaltar el listado de Faltas 
Administrativas Graves de los Servidores Públicos como de los actos vinculados con faltas administrativas graves, como se muestra en la siguiente tabla 1.

\section{Tabla 1.}

Cuadro comparativo de faltas administrativas graves de los servidores públicos y actos de particulares vinculados con faltas administrativas graves.

\begin{tabular}{|c|c|}
\hline \multicolumn{2}{|c|}{ LEY GENERAL DE RESPONSABILIDADES ADMINISTRATIVAS } \\
\hline $\begin{array}{l}\text { Capítulo II } \\
\text { De las faltas administrativas graves de los } \\
\text { Servidores Públicos. } \\
\text { Artículos del } 52 \text { al } 64 \text { bis. }\end{array}$ & $\begin{array}{l}\text { Capítulo III. De los actos de particulares } \\
\text { vinculados con faltas administrativas graves. } \\
\text { Artículos del } 66 \text { al } 72 \text {. }\end{array}$ \\
\hline $\begin{array}{l}\text { Cohecho. } \\
\text { Peculado. } \\
\text { Desvío de recursos públicos. } \\
\text { Utilización indebida de información. } \\
\text { Abuso de funciones. } \\
\text { Actuación bajo conflicto de interés. } \\
\text { Contratación indebida. } \\
\text { Enriquecimiento oculto u ocultamiento de } \\
\text { conflicto de Interés. } \\
\text { Simulación de acto jurídico. } \\
\text { Tráfico de influencias. } \\
\text { Encubrimiento. } \\
\text { Desacato. } \\
\text { Nepotismo. } \\
\text { Obstrucción de Justicia }\end{array}$ & $\begin{array}{l}\text { Soborno. } \\
\text { Participación ilícita en procedimientos } \\
\text { administrativos. } \\
\text { Tráfico de influencias. } \\
\text { Utilización de información falsa. } \\
\text { Colusión. } \\
\text { Uso indebido de recursos públicos. } \\
\text { Contratación indebida de ex servidores } \\
\text { públicos. }\end{array}$ \\
\hline
\end{tabular}

Fuente: Elaboración propia con datos de la LGRA (Unión, LEY GENERAL DE RESPONSABILIDADES ADMINISTRATIVAS , 2016).

La acepción de las faltas administrativas graves de los Servidores Públicos se señalan en la LGRA (Unión, LEY GENERAL DE RESPONSABILIDADES ADMINISTRATIVAS , 2016), se muestran a continuación:

Cohecho, la LGRA en su art. 52 hace mención que comete este delito el servidor público que obtiene un beneficio personal al aceptar o pretender obtener para él u otras personas que puedes ser e dinero o bienes, como también verse beneficiado al obtener un bien a un precio menor de mercado, lo cual puede extenderse hacia su cónyuge, parientes o terceros. 
Peculado, el servidor público comete éste delito cuando hace uso indebido o bien se apropia de los recursos del gobierno, como se explica en la LGRA en su art.53 indica "materiales, humanos o financieros, sin fundamento jurídico o en contraposición a las normas aplicables".

Desvío de recursos públicos, la LGRA en su art. 54 menciona la situación en que el servidor público solicite, autorice o realice la asignación de recursos públicos que no estén señalados en una normativa en favor de él o de terceras personas cae en esta responsabilidad administrativa

Utilización indebida de información, el uso de información privilegiada para obtener beneficios en cuanto a la adquisición de bienes o de un empleo para sí o personas cercanas al servidor público, se señala en el art. 55 de la LGRA

Información privilegiada, en el caso de que por su puesto el servidor público haga uso de información inherente a su cargo o bien sea reservada, se extiende hasta después de haber ocupado su empleo por un año, de acuerdo a lo señalado en el art. 56 de la LGRA

Abuso de funciones, se verá involucrado el servidor público cuando se extralimite de las funciones de su puesto, cargo o comisión, pudiendo brindar un beneficio a su persona o a terceros cercanos, como se menciona en el art. 57 de la LGRA

Actuación bajo Conflicto de Interés, esta responsabilidad es señalada en el art. 58 de la LGRA, cuando se encuentre el servidor público bajo conflicto de interés para dar curso a un trámite o autorización o resolución que competen a su puesto, cargo o comisión, siendo que el "conflicto de interés es la posible afectación del desempeño imparcial y objetivo de las funciones de los servidores públicos" (art. 3 LGRA). Cabe señalar que el servidor público en el momento de darse cuenta de una situación de conflicto de interés lo hará de su conocimiento a su jefe inmediato superior para ser relevado de ese encargo que le causa conflicto.

Responsable de contratación indebida, cuando el servidor público no observe los requisitos y formas en los procesos de adjudicación o bien autorice a quien o quienes estén 
inhabilitados para realizar una contratación, como también de ocupar un puesto, lo que se menciona en el art. 59 de la LGRA.

Enriquecimiento oculto u ocultamiento de Conflicto de Interés, al no presentar los datos verdaderos en su declaración de situación patrimonial o de interese, el servidor pública caerá en responsabilidad al ocultar el incremento de su patrimonio sin una cabal explicación, como se señala en el art. 60 de la LGRA.

Tráfico de influencias, se menciona en el art. 61 de la LGRA, que el servidor público puede ubicarse en esta responsabilidad al utilizar su cargo para que otro servidor público favorezca una resolución, autorización o niegue un acto propio de su encargo, generando con ello un beneficio personal o hacia terceros.

Responsable de encubrimiento, es la responsabilidad del servidor público cuando no da a conocer faltas administrativas en el ejercicio de sus funciones, siendo su intención ocultarlas, como se señala en el art. 62

Desacato, al no atender un requerimiento de carácter de control interno, jurisdiccional, electoral u otras, de información falsa o bien retrase la entrega de información solicitada por autoridad competente, como lo refiere el art. 63 de la LGRA

Nepotismo, es una falta administrativa grave que comete el servidor público cuando designa, contrata en cualquiera de las modalidades de contratación a personas que tengan lazos de parentesco por consanguinidad hasta el cuarto grado y por afinidad hasta el segundo, también se considera el vínculo del matrimonio o el concubinato, como se indica en el art. 63 Bis de la LGRA.

Obstrucción de justicia, se considera esta responsabilidad administrativa cuando los servidores públicos responsables de la investigación, substanciación y resolución de las faltas graves simulen ser faltas no graves; no inicien el procedimiento en el tiempo establecido por la ley; o bien revelen datos confidenciales que perjudiquen el proceso, como se cita en las fracciones I, II y III del art. 64 de la LGRA 
Es relevante en este estudio, considerar la tipificación de las faltas graves vinculadas a particulares plasmadas en la LGRA y son las siguientes (Unión, LEY GENERAL DE RESPONSABILIDADES ADMINISTRATIVAS , 2016):

Soborno, los particulares se vinculan a esta responsabilidad administrativa en el momento que prometen, ofrecen o entreguen un beneficio en dinero o bienes, a cambio de recibir una autorización o beneficio a cambio, por la posición que ocupa el servidor público, situación señalada en el art. 66 de la LGRA.

Participación ilícita en procedimientos administrativos, se vincula al particular que estando impedido para participar en procedimientos administrativos federales, estatales o municipales, realice acciones para participar en ellos, siendo que está impedido por la ley o alguna situación especial señalada en resolución de autoridad. Por otra parte cuando el particular intervenga en nombre de otra persona que se encuentre impendido, obteniendo algún beneficio por ello, como se menciona en el art. 67 de la LGRA

Tráfico de influencias para inducir a la autoridad, cuando un particular utilice su poder económico o político para ser beneficiado con una autorización o contratación, en donde interviene la voluntad del servidor público, como se puede apreciar en el art. 68 de LGRA.

Utilización de información falsa, se vincula al particular que presenta información falsa o alterada para ser viable su participación en un proceso administrativo, como también la obstrucción de facultades de investigación de faltas graves, retrase la investigación o no proporcione información, esta responsabilidad se menciona en el art. 69 de la LGRA.

Colusión, es la vinculación a particulares por acciones en las que acuerden uno o más sujetos, en materia de contratación pública, obteniendo beneficios o ventajas en el proceso de adjudicación, situación señalada en el art. 70 de la LGRA

Uso indebido de recursos públicos, se vincula al particular que realice actos mediante los cuales se beneficie de recurso públicos siendo estos bienes, dinero o recurso humanos de los que ha tenido acceso por algún proyecto en específico, como también el no rendir cuentas de proyecto autorizado y recibido, contenido en el art. 71 de la LGRA. 
Contratación indebida de ex Servidores Públicos, en caso de que el particular contrate a servidores públicos que han dejado o han sido removidos de su puesto, cargo o comisión, para obtener información privilegiada obteniendo con ello un beneficio, como se menciona en el art. 72 de la LGRA

Por otra parte, la LGRA contempla casos de particulares en situación especial, como lo son candidatos a cargo de elección popular, miembros de equipo de campaña electoral o de transición de las administraciones públicas, o bien líderes de sindicatos cuando se coloquen en el supuesto del cohecho.

La prescripción de las faltas administrativas no graves es de tres años a partir del día siguiente en que se haya cometido o bien a partir del momento en que hubieren cesado, mientras que las faltas administrativas graves prescribirán a los siete años.

Las sanciones que se imponen en caso de cometer faltas administrativas graves están clasificadas para servidores públicos y en el caso de particulares se muestran para personas físicas y para personas morales

Las faltas administrativas tanto no graves, como graves ameritan sanciones, las cuales se señalan a continuación para los servidores públicos, son las que se señalan a continuación en la tabla 2:

Tabla 2

Sanciones aplicables a servidores públicos

\begin{tabular}{|c|c|}
\hline Faltas no graves & Faltas Graves \\
\hline ART. 75 LGRA & ART. 78 LGRA \\
\hline $\begin{array}{l}\text { I. Amonestación pública o privada; } \\
\text { II. Suspensión del empleo, cargo o comisión (de } \\
1 \text { a } 30 \text { días naturales) } \\
\text { III. Destitución de su empleo, cargo o comisión } \\
\text { IV. Inhabilitación temporal para desempeñar } \\
\text { empleos, cargos o comisiones en el servicio } \\
\text { público y para participar en adquisiciones, } \\
\text { arrendamientos, servicios u obras públicas (no } \\
\text { será menor de tres meses ni mayor de un año) }\end{array}$ & $\begin{array}{l}\text { I. Suspensión del empleo, cargo o comisión; } \\
\text { II. Destitución del empleo, cargo o comisión; } \\
\text { III. Sanción económica, y } \\
\text { IV. Inhabilitación temporal para desempeñar } \\
\text { empleos, cargos o comisiones en el servicio } \\
\text { público y para participar en adquisiciones, } \\
\text { arrendamientos, servicios u obras públicas. }\end{array}$ \\
\hline
\end{tabular}


Serán Secretarías y los Órganos internos de Serán impuestas al infractor una o más de control podrán imponer una o más de las las sanciones señaladas por el Tribunal sanciones

Administrativo

Fuente: Elaboración propia con datos de la Ley General de Responsabilidades Administrativas (Unión, LEY GENERAL DE RESPONSABILIDADES ADMINISTRATIVAS , 2016).

Las sanciones que corresponde a particulares, se muestran en la tabla 3

Tabla 3.

Sanciones a particulares vinculados con faltas administrativas graves

\begin{tabular}{|l|l|}
\hline Personas Físicas & Personas Morales \\
\hline ART. 81 F. I, LGRA & ART. 81 F. II, LGRA \\
\hline $\begin{array}{l}\text { a) Sanción económica que podrá alcanzar hasta } \\
\text { dos tantos de los beneficios obtenidos o, en } \\
\text { caso de no haberlos obtenido, por el } \\
\text { equivalente a la cantidad de cien hasta ciento } \\
\text { cincuenta mil veces el valor diario de la Unidad } \\
\text { de Medida y Actualización; } \\
\text { b) Inhabilitación temporal para participar en } \\
\text { adquisiciones, arrendamientos, servicios u } \\
\text { obras públicas, según corresponda, por un } \\
\text { periodo que no será menor de tres meses ni } \\
\text { mayor de ocho años; } \\
\text { c) Indemnización por los daños y perjuicios que podrá alcanzar hasta } \\
\text { ocasionados a la Hacienda Pública Federal, } \\
\text { local o municipal, o al patrimonio de los entes } \\
\text { públicos. }\end{array}$ & $\begin{array}{l}\text { cantidad de mil hasta un millón quinientas mil } \\
\text { veces el valor diario de la Unidad de Medida y } \\
\text { Actualización; } \\
\text { b) Inhabilitación temporal para participar en } \\
\text { adquisiciones, arrendamientos, servicios u } \\
\text { obras públicas, por un periodo que no será } \\
\text { menor de tres meses ni mayor de diez años; } \\
\text { c) La suspensión de actividades, por un } \\
\text { periodo que no será menor de tres meses ni } \\
\text { mayor de tres años, la cual consistirá en } \\
\text { detener, diferir o privar temporalmente a los } \\
\text { particulares de sus actividades comerciales, } \\
\text { económicas, contractuales o de negocios por } \\
\text { estar vinculados a faltas administrativas graves } \\
\text { previstas en esta Ley; } \\
\text { d) Disolución de la sociedad respectiva, la cual } \\
\text { consistirá en la pérdida de la capacidad legal } \\
\text { de una persona moral, para el cumplimiento } \\
\text { del fin por el que fue creada por orden } \\
\text { jurisdiccional y como consecuencia de la } \\
\text { comisión, vinculación, participación y relación } \\
\text { con una Falta administrativa grave prevista en } \\
\text { esta Ley; } \\
\text { e) Indemnización por los daños y perjuicios } \\
\text { ocasionados a la Hacienda Pública Federal, }\end{array}$ \\
\hline
\end{tabular}

Solís G. I., Aguilar V. H., Alcalá A.N. \& Solís R.M. 


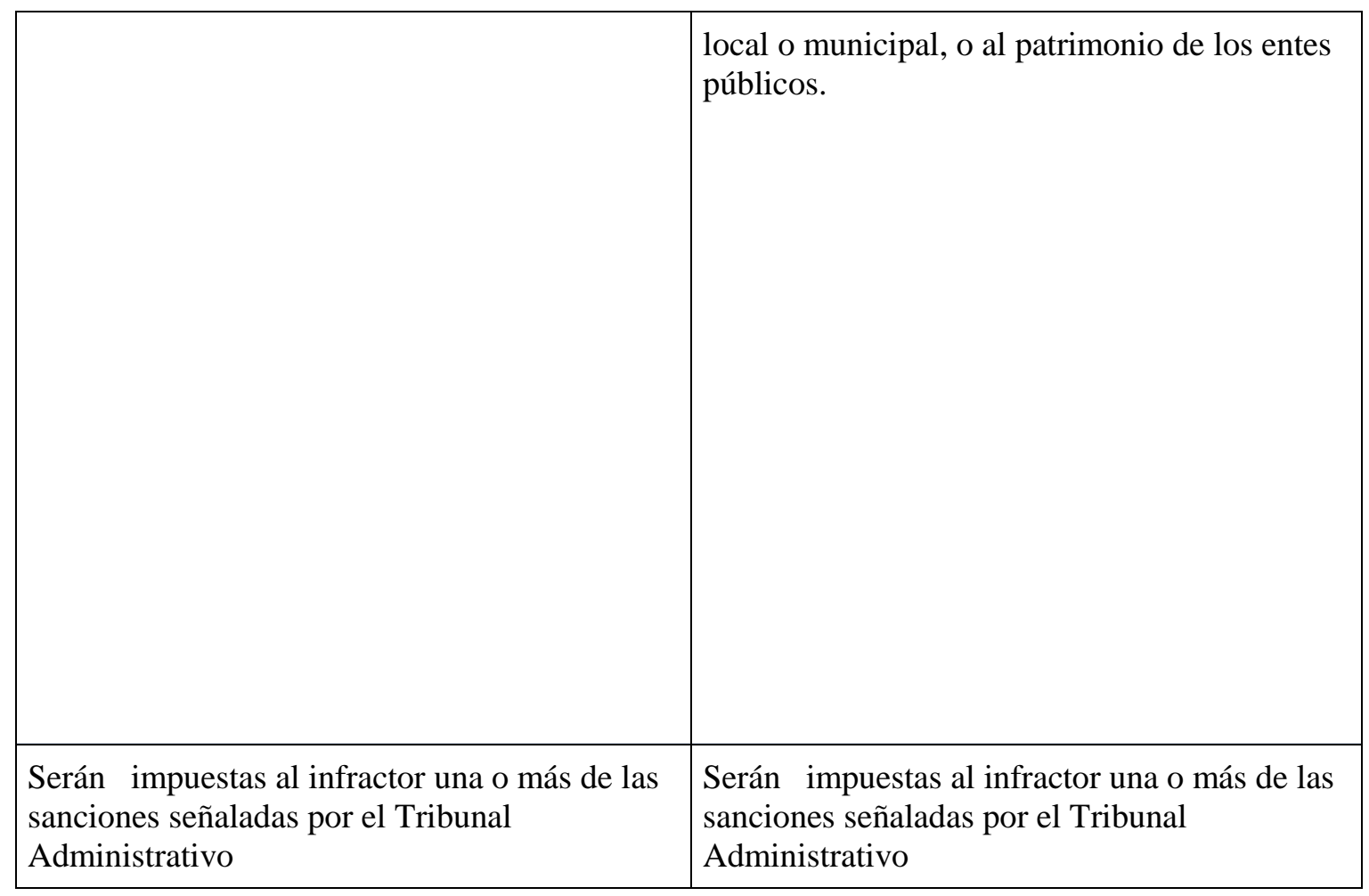

Fuente: Elaboración propia con datos de la Ley General de Responsabilidades Administrativas (Unión, LEY GENERAL DE RESPONSABILIDADES ADMINISTRATIVAS , 2016).

\section{4 Apreciación de la corrupción y conformación de estructuras para combatirla.}

La LGRA en caso de falta graves impone sanciones para los servidores públicos como también hacia los particulares personas físicas y personas morales, desde la vigencia de la ley de acuerdo a los datos mostrados en el portal INEGI, se puede apreciar los resultados que ha dado la vigencia de la LGRA, como vínculo del SNA y del SNF y producto de las acciones coordinadas a fin de prevenir, detectar y sancionar actos de corrupción en nuestro país, en donde estén involucrados servidores públicos y particulares. Se puede apreciar la respuesta al comportamiento de la corrupción en la tabla 4.

\section{Tabla 4.}

Comunicado de Prensa Núm. 644/19 5 de diciembre De 2019 


\begin{tabular}{|c|c|}
\hline $\begin{array}{l}\text { ESTADÍSTICAS A PROPÓSITO DEL DÍA } \\
\text { INTERNACIONAL CONTRA LA CORRUPCIÓN }\end{array}$ & CONFORMACIÓN DE ESTRUCTURAS \\
\hline $\begin{array}{l}\text { - En México, } 56.7 \% \text { de población de } 18 \text { años y } \\
\text { más considera que la corrupción es uno de los } \\
\text { problemas más importantes que enfrenta la } \\
\text { entidad federativa donde reside, solo por detrás } \\
\text { de la inseguridad y la delincuencia. } \\
\text { - Durante } 2017,14.6 \% \text { de la población adulta } \\
\text { que tuvo contacto con un servidor público sufrió } \\
\text { algún acto de corrupción, observándose un } \\
\text { aumento en la prevalencia de corrupción } \\
\text { respecto a } 2015 \\
\text { - En } 2018,17 \text { entidades contaron con Plan o } \\
\text { Programa Anticorrupción estatal, } 9 \text { indicaron } \\
\text { estar en proceso de integrarlo y } 6 \text { indicaron no } \\
\text { contar con uno. }\end{array}$ & $\begin{array}{l}\text { Respecto a la conformación de órganos } \\
\text { para la integración de los Sistemas } \\
\text { Locales Anticorrupción, } 31 \text { entidades } \\
\text { habían integrado el Tribunal de Justicia } \\
\text { Administrativa y } 30 \text { contaban con } \\
\text { Fiscalía Anticorrupción u homologa. No } \\
\text { obstante, los rezagos para integrar el } \\
\text { Comité de Participación Ciudadana, el } \\
\text { Comité Coordinador del Sistema, así } \\
\text { como la Secretaría Técnica del Sistema, } \\
\text { dejaban a ocho entidades sin la } \\
\text { conformación de todos los órganos del } \\
\text { Sistema Local Anticorrupción. }\end{array}$ \\
\hline
\end{tabular}

Fuente: Elaboración propia con datos del INEGI (2019).

Existe como dato aproximado de acuerdo a las denuncias recibidas por las administraciones públicas estales, que, por cada 100 denuncias, hubo 15 servidores públicos sancionados, lo que da certeza que las acciones propuestas en el combate a la corrupción se están llevando a cabo y que hay indicios de poder bajar los niveles de corrupción en la medida que se apliquen las sanciones señaladas en la LGRA. Lo anterior de acuerdo a datos de INEGI (Centro de Investigación y Docencia Económica, 2019), se muestra a continuación en la figura 2.

\section{Figura 2.}

Tasa Servidores públicos. 


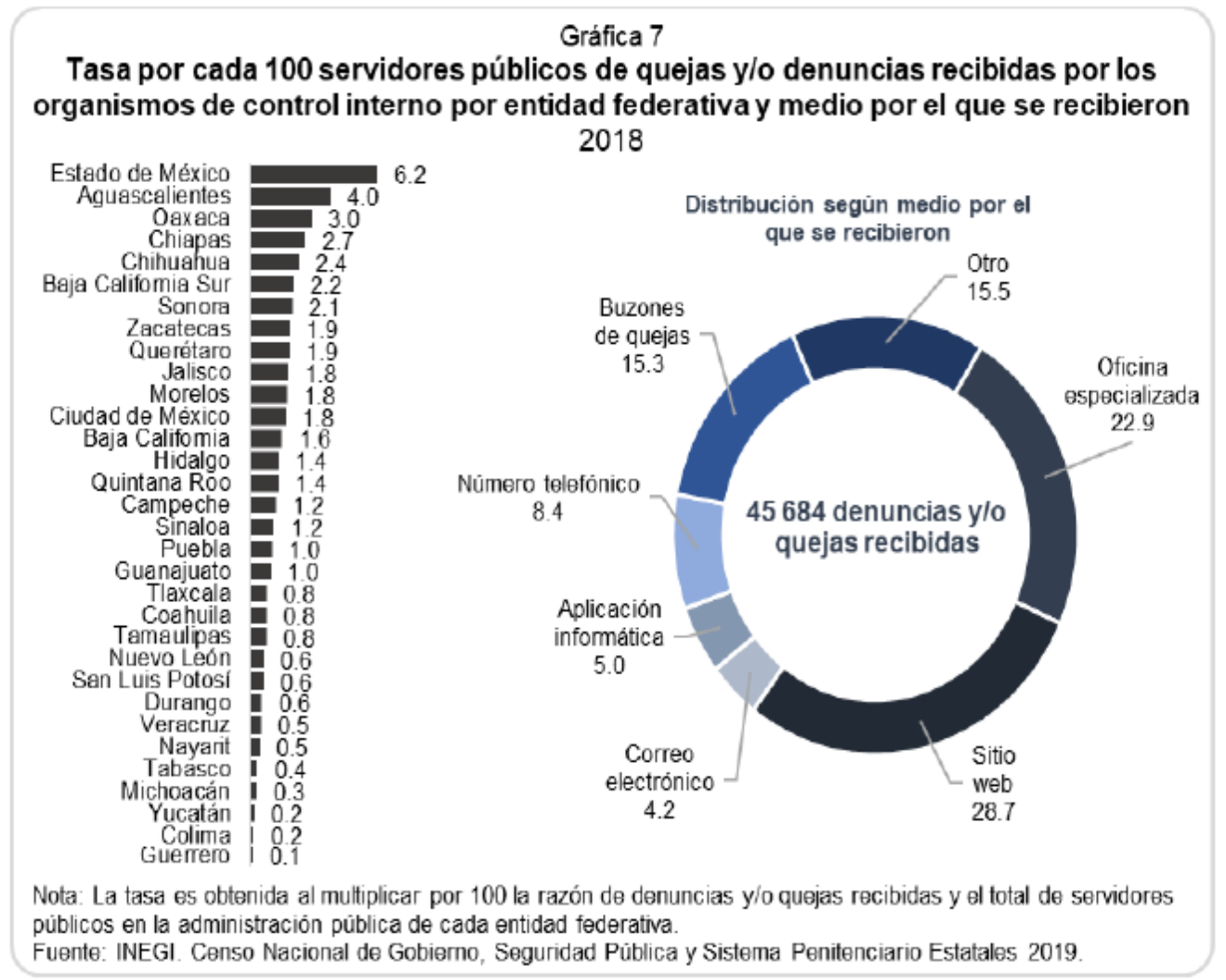

Fuente: INEGI, Estadísticas de comunicado de prensa del 5 de diciembre de 2019.

\section{METODOLOGÍA, TÉCNICAS Y MATERIALES EMPLEADOS}

El método utilizado en esta investigación es teórico, propio de las ciencias sociales y se centra en el estudio de estructuras del Sistema Nacional de Fiscalización, del Sistema Nacional Anticorrupción y el análisis estadístico del Instituto Nacional de Estadística y Geografía (INEGI) en relación a indicadores de la Corrupción y el combate a la misma, correlacionando los datos con el cumplimiento de la Ley General de Responsabilidades Administrativas, así como también la fundamentación de la responsabilidad administrativa.

\section{CONCLUSIONES}

Derivado del incremento de la corrupción en nuestro País ha sido necesario emprender acciones por parte del Estado para combatir la corrupción, la Ley General de 
Responsabilidades Administrativas (LGRA) nace como un compendio normativo fortaleciendo al Sistema Nacional de Fiscalización y el Sistema Nacional Anticorrupción, así como leyes y reglamentos, con el objeto de establecer lineamientos para el desarrollo de las actividades de los servidores públicos, estableciendo sanciones por incurrir en Responsabilidades Administrativas, de ahí la importancia de su observancia para dar cumplimiento de los fines de la Administración Pública. En lo que respecta al SNA, su puesta en marcha corresponde al conjunto de acciones coordinadas, con el fin de vigilar la correcta aplicación de los recursos con los que los entes gubernamentales realizan sus actividades, así como su correcto destino y aplicación.

Se considera que SNF y el SNA van en camino de dar resultados, su funcionamiento debe conducir a disminuir la corrupción en nuestro país, la LGRA surge con atribuciones para sancionar tanto a Servidores Públicos, como también a particulares, enmarcando las faltas graves y será la parte ejecutora de las acciones de los dos sistemas señalados y con ello alcanzar los objetivos propuestos, en el combate a la corrupción. Cabe señalar que las faltas graves de los servidores públicos estarán vinculadas con una falta del particular, por esa razón la LGRA tipifica las faltas administrativas graves de los servidores públicos y están señaladas en los artículos del 52 al 64 bis, como también de los particulares en los artículos del 66 al 72. Analizando esta vinculación, si un servidor comete el delito de "cohecho”, es indudable que por parte del particular comete el delito de "soborno"; como también cuando el servidor público incurre en el delito de "contratación indebida" el particular se coloca en el supuesto de "tráfico de influencias".

En la medida que la Ley General de Responsabilidades Administrativas (LGRA) tenga una mejor difusión impactará tanto a servidores públicos como a particulares sobre las acciones y actos que deben abstenerse de realizar, sobre todo las que constituyen faltas graves, la cuales se investigarán, calificarán y se sancionaran de acuerdo a la ley en mención, esta normativa solo es un parte del engranaje que se ha puesto en marcho desde el año 2015, con el surgimiento del Sistema Nacional de Fiscalización (SNF) y del Sistema Nacional Anticorrupción (SNA), que en conjunto con otras disposiciones han dado origen a datos sobre el número de investigaciones y número de servidores públicos sancionados, de acuerdo a los datos señalados en el comunicado de prensa de INEGI núm. 644/19 del 5 de 
diciembre de 2019, se señala que de cada 100 denuncias recibidas en 2018, 15 servidores públicos han sido sancionados, esto da una muestra que los esfuerzos coordinados para prevenir, denunciar y sancionar actos de corrupción y de las acciones emprendidas dan indicios de un cambio en la conciencia de quienes se encuentren frente a un acto de corrupción, tomen el camino correcto de denunciarlo o bien de no pretender llevarlo a cabo.

\section{PROPUESTA}

Tomando en consideración lo que se ha abordado en relación a la importancia de la Ley de Responsabilidades administrativas en el engranaje del Sistema Nacional de Fiscalización, fortalecido con el Sistema Nacional Anticorrupción que da origen a la ley en mención, es necesario abrir un abanico de posibilidades que prevengan la colusión y perpetración de hechos y actos de corrupción, además de los ya señalados, será un elemento muy importante continuar con los procesos de capacitación de los servidores públicos bajo una cultura de ética y responsabilidad administrativa, primero sensibilizando "el deber ser de toda persona", en segundo lugar promoviendo procesos efectivos de vigilancia a través de comités donde participen servidores públicos y ciudadanos, validando los procesos en el manejo de los recursos públicos, en donde se puedan incluir jóvenes estudiantes de licenciaturas afines a la administración pública con conocimiento de los mecanismos de rendición de cuentas y promoviendo que sea válido para su servicio social y práctica profesional.

\section{REFERENCIAS}

Hart, H. (1998). El Concepto del Derecho. Buenos Aires, Argentina: ABELEDO-PERROT S.A.

INEGI, I. N. (5 de Diciembre de 2019). INEGI. Obtenido de INEGI: https://www.inegi.org.mx/contenidos/saladeprensa/aproposito/2019/corrupcion2019_Nal.pd $\mathrm{f}$

INEGI, I. N. (19 de Diciembre de 2019). INEGI. Obtenido de INEGI: https://www.inegi.org.mx/contenidos/saladeprensa/aproposito/2019/corrupcion2019_Nal.pd $\mathrm{f}$

México, G. d. (2021 de Febrero de 2021). Consejo Nacional de Armonización Contable. Obtenido de Consejo Nacional de Armonización Contable: https://www.conac.gob.mx/

Unión, C. d. (18 de Julio de 2016). LEY GENERAL DE RESPONSABILIDADES ADMINISTRATIVAS . Obtenido de LEY GENERAL DE RESPONSABILIDADES ADMINISTRATIVAS : http://www.diputados.gob.mx/LeyesBiblio/pdf/LGRA_130420.pdf 
Unión, C. d. (18 de Julio de 2016). Ley General del Sistema Nacional Anticorrupción . Obtenido de Ley General del Sistema Nacional Anticorrupción :

http://www.diputados.gob.mx/LeyesBiblio/pdf/LGSNA.pdf 